\title{
Inflammaging is associated with shifted macrophage ontogeny and polarization in the aging mouse ovary
}

\author{
Zijing Zhang ${ }^{1}$, Florencia Schlamp², Lu Huang ${ }^{3}$, Haley Clark ${ }^{1}$ and Lynae Brayboy,4,5,6 \\ ${ }^{1}$ Department of Obstetrics and Gynecology, Division of Research, Women \& Infants Hospital of Rhode Island, \\ Providence, Rhode Island, USA, ${ }^{2}$ Department of Molecular Biology and Genetics, Cornell University, Ithaca, New \\ York, USA, ${ }^{3}$ Department of Microbiology and immunology, College of Veterinary Medicine, Cornell University, \\ Ithaca, New York, USA, ${ }^{4}$ Department of Obstetrics and Gynecology, Division of Reproductive Endocrinology and \\ Infertility, Women \& Infants Hospital of Rhode Island, Providence, Rhode Island, USA, ${ }^{5}$ Alpert Medical School of \\ Brown University, Providence, Rhode Island, USA and ${ }^{6}$ Department of Molecular Biology, Cell Biology and \\ Biochemistry, Brown University, Providence, Rhode Island, USA
}

Correspondence should be addressed to L Brayboy; Email: Lynae_brayboy@brown.edu

\begin{abstract}
The fertility of women declines sharply after age 35 and is essentially lost upon menopause at age 51 . The ovary plays an important part in aging-associated changes in women's physiology since it is an essential component of both the reproductive and endocrine systems. Several previous studies in mice have shown that the ovarian tissue goes through drastic changes over the course of aging and exhibits signs of aging-associated chronic inflammation (inflammaging), which may contribute to the marked decline of oocyte quality in aged individuals. To further examine aging-associated gene expression changes in the ovary and to characterize the development of inflammaging, we performed detailed transcriptomic analysis of whole ovaries from mice of six different age groups over the mouse reproductive lifespan and identified more than $\mathbf{5 0 0 0}$ genes with significant expression change over the course of aging. Intriguingly, we found aging-associated changes in the expression of several markers that indicate alterations in the composition of ovarian macrophages, which are known to be central players of inflammaging. Using flow cytometry, we analyzed and compared macrophage populations and polarization in young and old ovaries and found a significant increase in monocyte recruitment and macrophage alternative activation (M2) in the old ovaries compared to those in young. Our results are consistent with previous findings of aging-associated increase of fibrosis in the ovarian stromal extracellular matrix, and they provide new clues about the development of inflammaging in the mammalian ovary.

Reproduction (2020) 159 325-337
\end{abstract}

\section{Introduction}

A prerogative of the modern woman is to become a mother if and when she so desires. The advent of contraception has given women the opportunity to purposefully delay childbearing in order to allocate time and resources toward pursuing their aspirations. However, it is a long-known fact that the female fertility decreases with chronological age and ultimately diminishes when women reach menopause in their fifties. At advanced reproductive age, pregnancies are not only harder to achieve, but they are also associated with higher risks of adverse pregnancy outcomes (Heffner 2004, Johnson \& Tough 2017).

The deterioration of ovarian functionality is thought to lay at the center of this aging-associated loss of reproductive potential, as the ovarian reserve of oocytes gradually depletes, and the quality of oocytes significantly decreases over the course of aging. Studies of young and old oocytes in mice and human have established that eggs produced by aged individuals exhibit distinct signs of aberrant gene expression and metabolism (Grondahl et al. 2010, Ge et al. 2019) and are associated with increased incidence of meiotic errors (Chiang et al. 2010, Jones \& Lane 2013, Hornick et al. 2015).

The oocyte acquires most of its cytoplasmic content, and thus, its competence to complete meiosis and support pre-implantation embryogenesis, during its growth and maturation (Thomas \& Vanderhyden 2006). Throughout this developmental process, the oocyte is enclosed in individual follicles embedded in the ovarian tissue, constantly surrounded by somatic cells, some of which maintain direct cytoplasmic interactions with the oocyte (Moley \& Schreiber 1995, Thomas \& Vanderhyden 2006). Therefore, molecular and biochemical changes in the ovarian tissue may exert heavy influence on the quality of the eggs. And there is thus an urgent need for a better understanding of the aging-related alterations at cellular and molecular level that take place in the ovary. 
It is evident from the findings of several recent studies that the ovarian tissue environment goes through gradual alterations over the course of aging. One particularly interesting finding is that aged ovaries appear to exhibit distinct signatures of elevated inflammatory status, including increased expression of various proinflammatory cytokines and altered extra cellular matrix (ECM) profile that implicates extensive tissue fibrosis (Briley et al. 2016). Consistent with this, RNA sequencing analysis of follicles retrieved from young and old mice also indicates a widespread upregulation of immunerelated genes in the latter (Duncan et al. 2017).

These findings are quite intriguing, since elevation of basal inflammatory status has been established as one of the hallmarks of aging in the recent decades (Ferrucci et al. 2005, Salvioli et al. 2013, Kennedy et al. 2014). An inflammatory tissue environment is highly pathogenic, as many aging-related diseases, including arthritis, type-II diabetes and cardiovascular diseases, have been associated with chronic inflammation. Evidence also suggests that the presence of inflammatory cytokines and chemokines are promotive to tumor development (Germano et al. 2008, Mantovani et al. 2008, Colotta et al. 2009). In fact, several reports have provided evidence that local inflammation is disruptive to ovarian function and oocyte development. For example, a study by Banerjee and colleagues demonstrated that exposure to an elevated concentration of pro-inflammatory cytokine IL6 exerted a negative impact on both the spindle organization and chromosome alignment in metaphase II (MII) mouse oocytes, which suggests a direct connection between rampant cytokine activity and the decreasing meiotic competence of oocyte (Banerjee et al. 2012). In addition, evidence from other studies shows that obesity-induced activation of inflammatory pathways in the ovary might have disruptive impacts on follicular development and egg quality (Nteeba et al. 2014, Skaznik-Wikiel et al. 2016, Snider \& Wood 2019). Basing on these findings, it is reasonable to infer that the increasing chronic inflammation in the ovary may contribute to the reduction of egg quality, as well as the development of pathological conditions in the ovary over the course of aging.

Though both innate and adaptive immune cells are known to play active roles in the inflammatory response, inflammation is generally considered as a part of innate immunity and is initiated and mediated mainly by the innate immune cells that reside in the tissues. The most abundantly present types of innate immune cell in the ovary are macrophages (Wu et al. 2004), a highly diverse and plastic population of phagocytes that are important sources of various inflammatory mediators and have a broad role in the maintenance of tissue homeostasis. In response to the tissue microenvironment, macrophages can polarize to M1 (classically activated) macrophages that specialize in the removal of pathogens and damaged cells, or M2 (alternatively activated) macrophages that mainly serve to remodel ECM and facilitate tissue repair (Gordon \& Taylor 2005, Italiani \& Boraschi 2014, Russell et al. 2019). Intriguingly, M2 macrophages are known to deposit collagens to the ECM, which in turn promotes fibrogenesis and associated pathologies (Wynn \& Vannella 2016). Since aged ovaries exhibit widespread tissue fibrosis (Briley et al. 2016), it is curious whether the rise of basal inflammatory status in aged ovarian tissue is associated with aberrancy of macrophage activity. However, our knowledge on the changes of macrophage populations in ovarian tissue during aging is essentially barren.

In this study, we aim to investigate the development of inflammatory status in the ovary and examine the alterations of macrophage populations over the course of aging. By analyzing and comparing the transcriptomic profiles of ovaries retrieved from mice of 6 different age groups throughout the normal mouse lifespan, we established an atlas of ovarian gene expression changes over time. In addition to the striking upregulation of a wide variety of immune-related genes, we observed an opposing expression change pattern of genes associated with $\mathrm{M} 1$ and $\mathrm{M} 2$ macrophages during aging. Our subsequent examination of the macrophages in young and old ovaries using flow cytometry revealed a significantly smaller, but more heavily $\mathrm{M} 2$ polarized, and increasingly monocyte-derived macrophage population in the old ovary compared to that in the young. Our findings suggest a general shift of macrophage plasticity and ontogeny in the ovary during aging, which indicates that inflammaging-induced dysfunction in the ovary may be partially attributed to altered activities of tissue macrophages.

\section{Materials and methods}

\section{Animals}

All mouse ovaries were obtained from C57/BL6J mice kindly donated to us by our colleague Dr John Sedivy. All mice used in this study were extracted from the National Institute of Aging (NIA) aged mouse colony and maintained in compliance with Institutional Animal Care and Use Committee (IACUC) protocol number 19-01-0005, which is approved by the IACUC at Brown University. The mice were maintained under 12-h light/darkness cycles on a standard diet.

\section{RNA sequencing}

Ovaries from three virgin female C57/BL6J mice of six different age groups (3 months, 6 months, 9 months, 12 months, 15 months and 18 months) (a total of 18 mice) were harvested and immediately flash frozen using liquid nitrogen. The RNA extraction, rRNA depletion, library preparation, sequencing, and read mapping were all performed by Genewiz Inc. (Plainfield, NJ, USA) with the standard RNAseq service package. $2 \times 150$ bp paired end sequencing was performed on an Illumina HiSeq platform with >350 M paired reads/lane. 


\section{Statistical analysis}

RNA sequencing read count data were analyzed using DESeq2 R-package (Love et al. 2014). Principal component analysis was performed after regularized-logarithm transformation (rlog) on gene counts. Differential expression analysis was performed using two models for the better capture of differentially expressed genes with different expression pattern changes. First, we identified genes with linear expression change patterns over time by comparing the design formula ' 1 + time' against the reduced ' $\sim 1$ ' using a likelihood ratio test (LRT). Next, we identified genes whose expression levels rise and fall (or fall and then rise) in a non-linear manner using a quadratic model by comparing the design formula ' $\sim 1+$ time $+\mathrm{I}\left(\mathrm{time}^{2}\right)^{\prime}$ versus reduced ' $\sim 1$ ', using LRT. Genes that show significant fitness to either the linear or quadratic model were deemed as differentially expressed over the course of aging (a total of 5749 differentially expressed genes were identified). Row Z-score was calculated based on rlog transformation and was used for the construction of the heatmap and each gene was scaled using pheatmap R-package (https://cran.rproject.org/ web/packages/pheatmap/pheatmap.pdf).

To obtain the trend of expression change of each gene, we performed a pairwise comparison of each later time point $(6,9$, 12,15 , and 18 months) against the first time point (3 months) using formula ' time' in a discrete manner, and performed Wald test contrasts for each pairwise comparison.

Gene Ontology analysis was performed with the Panther Overrepresentation Test (Mi et al. 2019), using the GO-Slim Biological Process annotation data set and FDR $<0.05$ from Fisher's exact test.

Gene Set analysis was done using the GSA R-package (Efron \& Tibshirani 2007).

Pathway gene memberships were assigned using Gene Ontology Annotations of mouse markers, which was downloaded from MGI Jackson Laboratory website (http:// www.informatics.jax.org/downloads/reports/index.html\#go). Normalized counts for all three replicates were compared against the first time point (3 months) using a two-class unpaired vector. FDR was estimated using permutations. Only pathways with $\mathrm{FDR}<0.05$, score $>2$, with 5 or more gene membership from our full dataset were kept.

\section{Ovarian cell isolation}

Ovarian cells were isolated via enzymatic digestion. Briefly, ovaries were removed and digested in $0.5 \%$ BSA/PBS solution containing $250 \mathrm{U} / \mathrm{mL}$ collagenase IV (Worthington, Columbus, $\mathrm{OH}, \mathrm{USA}$ ) at $37^{\circ} \mathrm{C}$ for 30 min using a gentleMacs dissociator (Miltenyi Biotec). The suspension was washed and then passed through a $70 \mu \mathrm{m}$ cell strainer.

\section{Flow cytometry}

Ovarian cell suspensions were incubated with Fc block (eBioscience, San Diego, CA, USA) for $15 \mathrm{~min}$. For surface staining, cells were then counted and incubated for $20 \mathrm{~min}$ in the dark with fluorophore-conjugated antibodies against mouse MerTK (DS5MMER), CD11b (M1/70), F4/80 (BM8),
CD64 (X54-5/7.1), MHCII (M5/114.15.2), CD45 (2D1), Ly6C (AL-21) and fixable viability dye from Thermo Fisher Scientific, BD Biosciences (Franklin Lakes, NJ, USA) and BioLegend (San Diego, CA, USA). For intracellular staining, cells were fixed with $4 \%$ paraformaldehyde (PFA) and incubated in permeabilization buffer (Thermo Fisher Scientific) before staining with an antibody against mouse RELM- $\alpha$ (PeproTech, Rocky Hill, NJ, USA) and secondary anti-rabbit Alexa Fluor 647 (Life Technologies). The Foxp3/Transcription Factor Staining buffer set (eBioscience) was used for Ki67 staining. Samples were acquired with a FACSArialllu flow cytometer (BD) at Flow Cytometry Facility at Brown University. Data were analyzed with the Flow)o software (TreeStar Ilc., Ashland, OR, USA).

\section{Statistical analysis}

The statistical information of our results, including $n$, mean, $P$ values, and error bars is specified in the figure legends. The statistical analysis of the results was conducted using Student's $t$ test using Prism 6.0 (GraphPad Software).

\section{Results}

\section{Ovarian aging is accompanied by the drastic upregulation of immune-associated genes}

To better understand the changes in molecular environment and immune activity that take place in the ovarian tissue during aging, we first set out to establish an atlas of aging-associated gene expression changes in the ovary. Using RNA sequencing technology, we analyzed and compared the transcriptomes of ovaries retrieved from virgin mice of six different age groups (3 months, 6 months, 9 months, 12 months, 15 months and 18 months) that cover the majority of the normal mouse lifespan.

A total of 22,086 genes were captured with good quality read counts across all samples (Supplementary Table 1, see section on supplementary materials given at the end of this article). We first examined the general variation in the gene expression profile among different samples by visualizing the dataset using principal component analysis (PCA). The top two principal components (PC1 and PC2) accounted for 78 and $10 \%$ of the total variance in gene expression among the samples respectively (Fig. 1A). It is apparent from the PCA plot that the three biological replicates for each age group cluster close to each other, which indicates a reasonably high correlation among replicate gene expression levels. We also noticed that the variation among replicates within the same age group appears to increase over time, which may suggest that the regulation of gene expression in the ovary becomes more variable over the course of aging. Samples from different age groups are generally more distant from each other, and the spatial distribution of the samples across PC2 seem to correspond to age of samples (Fig. 1A). Unexpectedly, we observed close spatial proximity between samples 


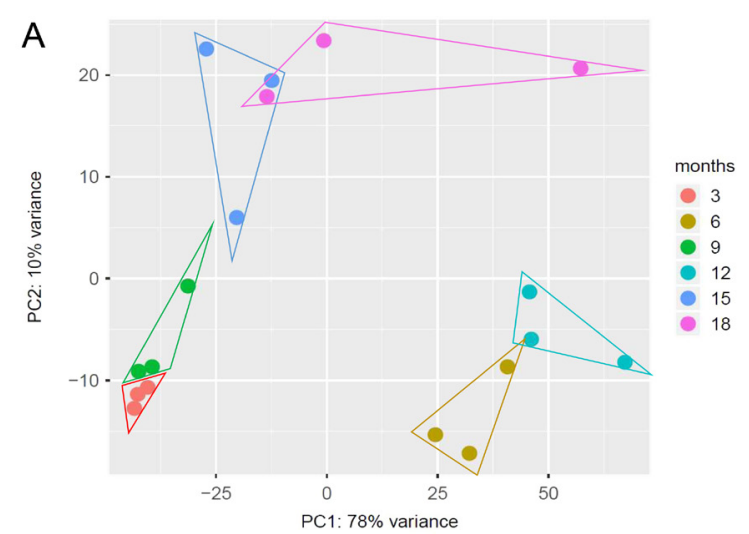

B Regularly expressed genes
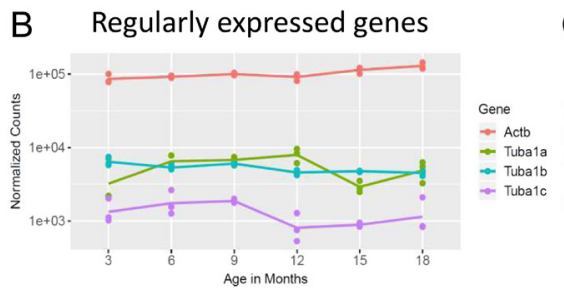

C

Oocyte-specific genes

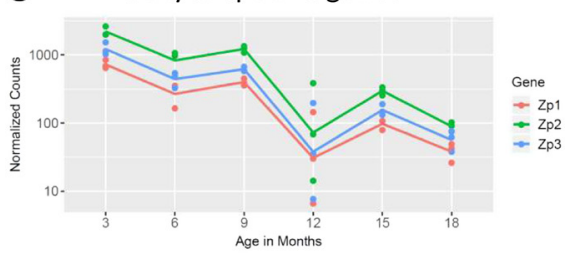

Figure 1 RNA sequencing analysis reveals drastic transcriptomic changes over the course of aging. (A) The principal component analysis of the ovarian transcriptomic data of the six age groups. The analysis was performed using the normalized gene counts (normalization performed using DEseq2). (B) Line chart that illustrates the expression change of ubiquitously expressed genes (ActB, Tuba1a, Tuba1b, Tuba1C) over the six time points. (C) Line chart that illustrates the expression change of oocyte-specific genes (Zp1, Zp2, Zp3) over the six time points. from 3- and 9-months age groups as well as that from 6- and 12-months age groups, which indicates close resemblance of the ovarian transcriptomic profile between these time points. It is possible that the larger transcriptomic variance between the neighboring time points among the first four age groups is a result of slight differences in the stages of estrous cycle.

Next, we evaluated the validity of the dataset by examining the read count changes of genes whose expression behaves in a predictable way during aging. As we expected, the normalized counts of ubiquitously expressed genes such as $\beta$-actin and tubulins vary little over time (Fig. 1B), while that of the egg-specific zona pellucida proteins $Z p 1, Z p 2$ and $Z p 3$ decline markedly with increasing age (Fig. 1C), which is consistent with the aging-associated depletion of ovarian reserve.

Next, we identified genes that show meaningful patterns of expression changes over the six time points. We fitted the dataset with both a linear and a polynomial quadratic model to effectively capture different types of expression changes over the course of aging (Fig. 2A). A total of 5749 genes exhibit statistically significant fit to either the linear or the quadratic model (Supplementary Table 2), indicating that they are likely differentially regulated during aging. Based on the normalized counts of these differentially expressed genes across the 18 samples, we constructed a heatmap to visualize the aging-associated gene expression changes in the ovary (Fig. 2B). It is apparent from the heatmap that the vast majority of the differentially expressed genes exhibit uni-directional changes (either increase or decrease) over time. The hierarchical clustering segregated the genes into two distinct clusters. The expression level of genes in cluster 1 is relatively high in young ovary and significantly decreases over the course of aging, while that of genes in cluster 2 exhibit an opposite pattern of change.

We next performed GO enrichment analysis on the two clusters of differentially expressed genes to examine their functional signatures (Mi et al. 2017). Cluster 1 of the differentially expressed genes exhibits a strong enrichment of terms related to spindle and chromosome organization, DNA damage repair and DNA replication. Interestingly, this cluster of genes is negatively enriched in terms associated with immune responses, suggesting that few immune-related genes exhibit reduced expression during aging (Fig. 2C). On the other hand, cluster 2 presents an almost completely opposite enrichment result to that of cluster 1 , as terms associated with immune responses are highly enriched, while terms for the regulation of chromatin organization and protein translation are negatively enriched. We noted that regulation of $\mathrm{T}$ cell activity, inflammatory response and cytokine production are among the most overrepresentative terms in genes that are upregulated in the aged ovary. The enrichment of these terms may suggest that the activity of both adaptive and innate immune systems rises in the ovarian tissue over the course of aging. Since inflammaging is a sterile inflammatory process, the extensive upregulation of genes related to adaptive immunity is particularly curious and will be an interesting subject for further study.

Next, we characterize the temporal behavior of known pathways over the course of aging, by performing gene set analysis at each time point compared to the first time point (3 months). Consistent with the results from the enrichment analysis, we found strong decline of various pathway gene sets related to spindle organization and chromosome 


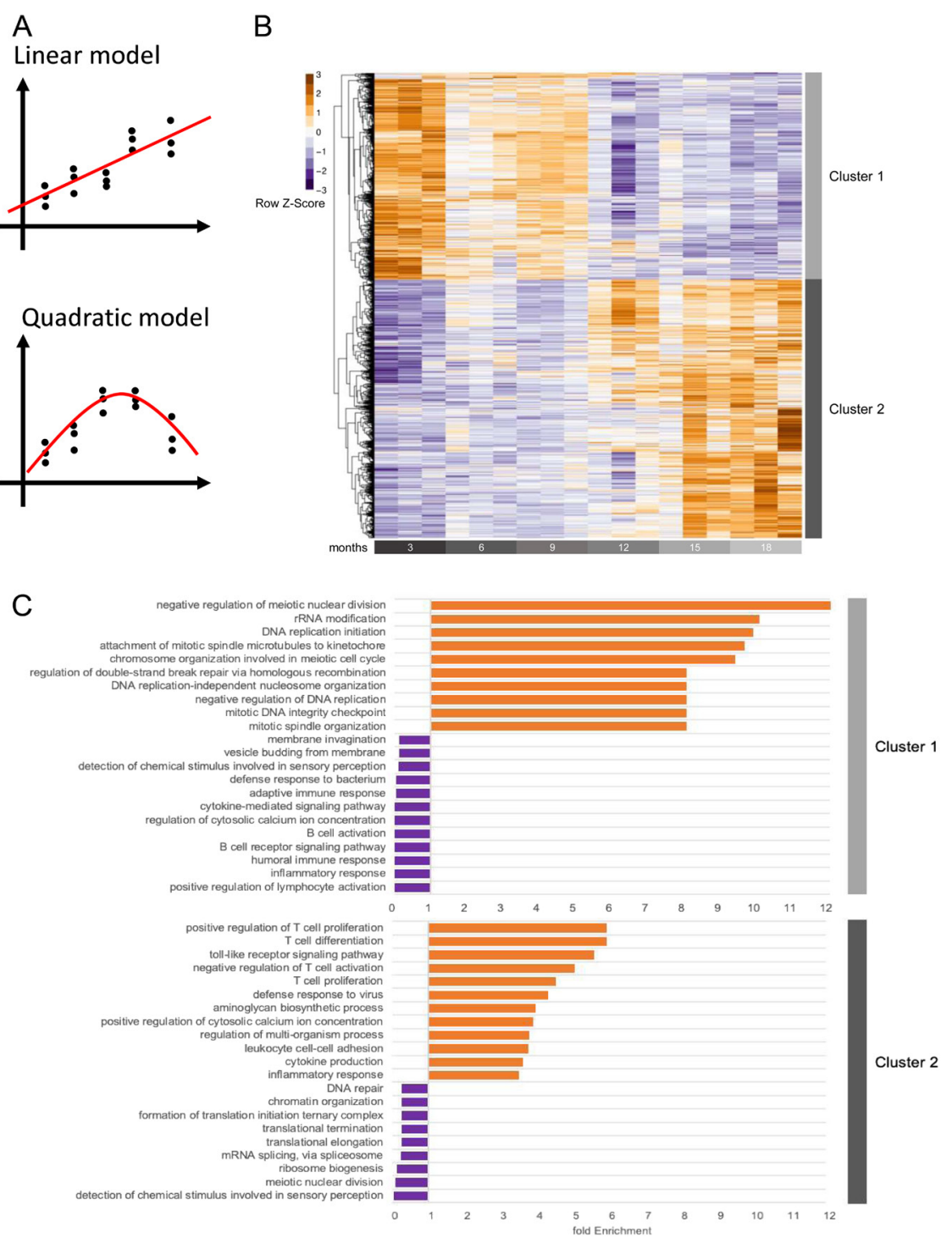

Figure 2 Immune-related genes are drastically upregulated in the ovary during aging. (A) Schematic drawing of exemplary gene expression change patterns that fit linear and quadratic model. (B) Heatmap of all genes that are differentially expressed over the course of aging. The rows correspond to genes, and columns correspond to samples. The plot was generated with the row Z-score that was calculated based on normalized counts. Orange and purple represent high and low values respectively. The list of the significantly differentially expressed genes and the associated statistics can be found in Supplementary Table 2. (C) The GO enrichment analysis of Cluster 1 and Cluster 2 genes. The fold enrichment of the top ten most enriched terms and top ten most negatively enriched terms for each cluster were plotted. organization mostly at mid to late time points, and an overall upregulation of immune related pathways (Fig. 3). Notably, the most upregulated pathways are dominated by terms associated with innate immunity, such as antigen processing and presentation, activation of innate immune response, and leukocyte cell-cell adhesion (Fig. 3). These results suggest that innate immunity might be dominating the rising immune activity during ovarian aging, which is consistent with aging-associated inflammation.

In summary, our results suggest that ovarian aging is accompanied by drastic transcriptomic changes and an overall upregulation of genes associated with both adaptive and innate immune responses.

\section{Markers of type 2 inflammatory response and M2 macrophages show elevated expression in aged ovaries}

Since the rise of immune activity represents a predominant aspect of the aging-associated transcriptomic changes in the ovary, we set to further investigate the nature of this immune elevation. We examined the RNA sequencing dataset for gene expression changes that are telltale signs of alterations in immune cell activity. Specifically, we focused on the genes that are associated with macrophages mainly for two reasons: (1) The macrophage is the most abundant type of immune cell in the ovarian tissue and has been shown to play vital roles in ovarian tissue organization (Wu et al. 2004, Turner et al. 2011), and (2) the activity of M2 macrophages is associated with chronic inflammation and tissue fibrosis, a condition that is reported to present in the ovarian tissue at old age (Briley et al. 2016). Thus, it is highly likely that the activity and polarization of ovarian macrophages change over the course of aging.

Macrophages can be alternatively activated into M2 macrophages by cytokine stimuli such as Interleukin-4 (IL4) and-13 (IL13) (Stein et al. 1992, Doherty et al. 1993, Doyle et al. 1994, Van Dyken \& Locksley 2013). To infer 


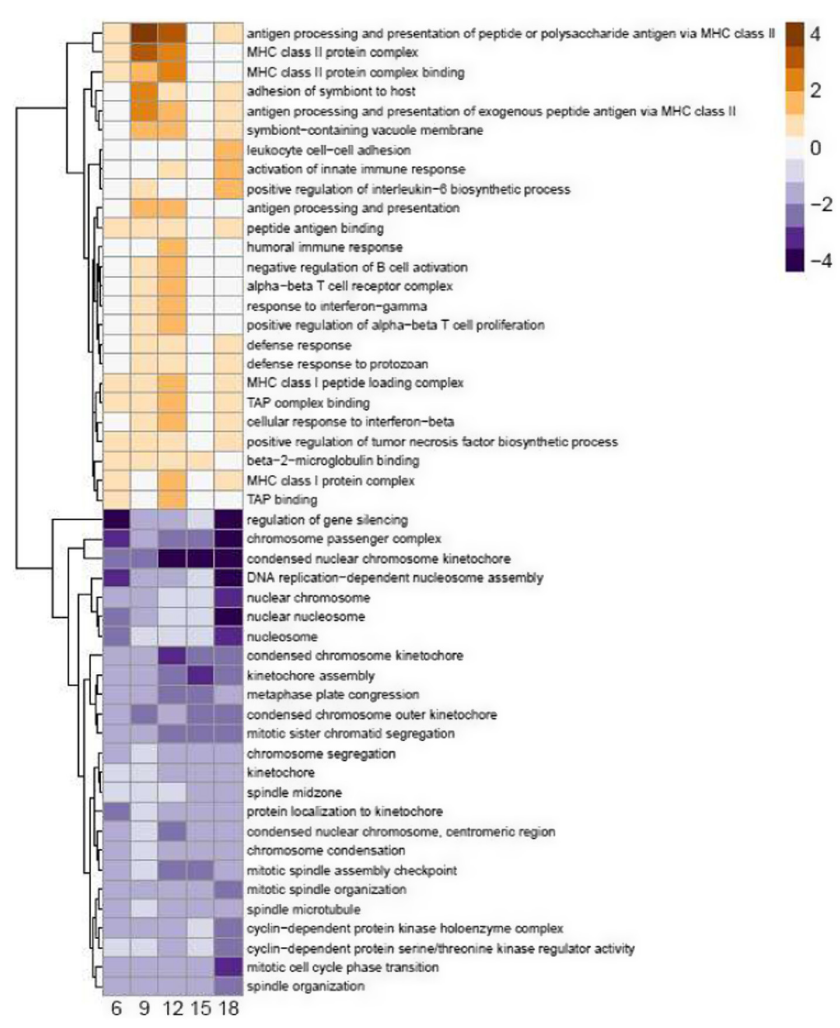

Figure 3 Pathway analysis of aging-associated gene expression changes. Each column represents an interval between a later time point $(6,9,12,15$, or 18 months) and 3 months. Gene expression fold changes of each interval was generated by comparing normalized gene read counts at each time point to that at 3 months. The color intensity of each pathway in each interval reflects the enrichment score of the pathway among genes that are up (orange) or downregulated(blue) in that interval.

the activity of IL4 and IL13 signaling in the ovarian tissue during aging, we first examined the expression level of IL4 receptor (I/4ra) and IL13 receptor subunit alpha 1 (II13ra1). Consistent with the upregulation of IL4 and IL13 signaling, the expression of both //4ra and //13ra 1 increase over the six time points with an almost overlapping pattern (Fig. 4A). Intriguingly, we also found that the expression of IL13 receptor subunit alpha 2 (I/13ra2), which is a known to act as a competitive "decoy" receptor that is inhibitory to IL13 signaling (Wood et al. 2003, Lupardus et al. 2010), decreases over the course of aging (Fig. 4B). This downregulation of inhibitory //13ra2 provides further evidence for an upsurge of IL4 and IL13 signaling in the ovary during aging, the activity of which may lead to an increase in the M2 polarization of ovarian macrophages. Indeed, we found that the expression level of classic M2 macrophage markers Arginase-1 (Arg1) is upregulated in aged ovaries (Fig. 4C). Consistent with that, RELM- $\alpha$ (Retnla), another marker for M2 macrophages, also shows a trend of increased expression over the 6 time points. In contrast, the expression of nitric oxide synthase 1 (Nos 1) and 2 (Nos2), which are markers for M1 macrophages, decline prominently over the six time points. These results provide further evidence for increasing M2 polarization of ovarian macrophages and suggest a shift of macrophage polarization from M1 to M2.

\section{Ovarian macrophages exhibit increased M2 polarization in the aged ovary}

The elevated expression of M2 macrophage markers in the aged ovary may be the consequence of increasing the number of M2 macrophages or the enhanced alternative activation, or both. To characterize the dynamics and activation status of ovarian macrophages during aging, we identified and analyzed macrophages in ovaries of young (3 months) and old (15 months) mice using multicolor flow cytometry. We first developed a flow cytometric gating protocol based on previous analysis of gene expression in tissue macrophages from various mouse organs (Gautier et al. 2012). Coexpression of MerTK and CD64 specifically identifies all macrophages in various tissues (Gautier et al. 2012), and thus enabled us to identify ovarian macrophages, which also express F4/80, a pan marker of macrophages (Fig. 5A).

Strikingly, we observed a significant drop of the total number of macrophages in old ovaries compared to that in young (Fig. 5B), which indicates a general decline of macrophage presence in the ovary at old age. We then examined the polarization of macrophages in young and old ovaries. The expression of secretory protein RELM- $\alpha$ is a hallmark of alternatively activated (M2) macrophages (Pine et al. 2018). Since we observed a very low level of signal of iNOS expression in flow cytometric analysis (data not shown), we used major histocompatibility complex II (MHCII), as an alternative marker for classically (M1) activated macrophages. MHCII is highly expressed in M1 macrophages and has been used as the indicator for M1 polarization in tissue macrophages (Chavez-Galan et al. 2015, Eastman et al. 2015, Cheng et al. 2019, Reidy et al. 2019). Intriguingly, we observe a significant increase in the proportion of RELM- $\alpha^{+}(21.8 \pm 6.15 \%$ in young and $43.9 \pm 13.9 \%$ in old, $P=0.0329$ ) (Fig. 5C) and a marked decrease in the proportion of $\mathrm{MHClI}^{+}$cells $(92.4 \pm 3.12 \%$ in young and $74.4 \pm 3.01 \%$ in old, $P=0.001$ ) (Fig. 5D) among total macrophages in the old ovaries. In line with this result, the median fluorescence intensity (MFI) of RELM- $\alpha$ signal showed a strong, though not statistically significant, increasing trend in the old ovary $(P=0.059)$, while the MFI of MHCII signal decreased significantly in the old ovary $(P=0.0101)$. This finding is consistent with the increased expression of IL4 and IL13 receptors and the M2 markers reflected by our RNAseq dataset and suggests an increased polarization of the ovarian macrophages toward M2 phenotype during ovarian aging.

We then proceeded to further examine the changes in the composition of macrophage populations in the young and old ovary. Macrophages that are present in tissues can be categorized into at least two classes based on their origins. Macrophages that arise from yolk sac 

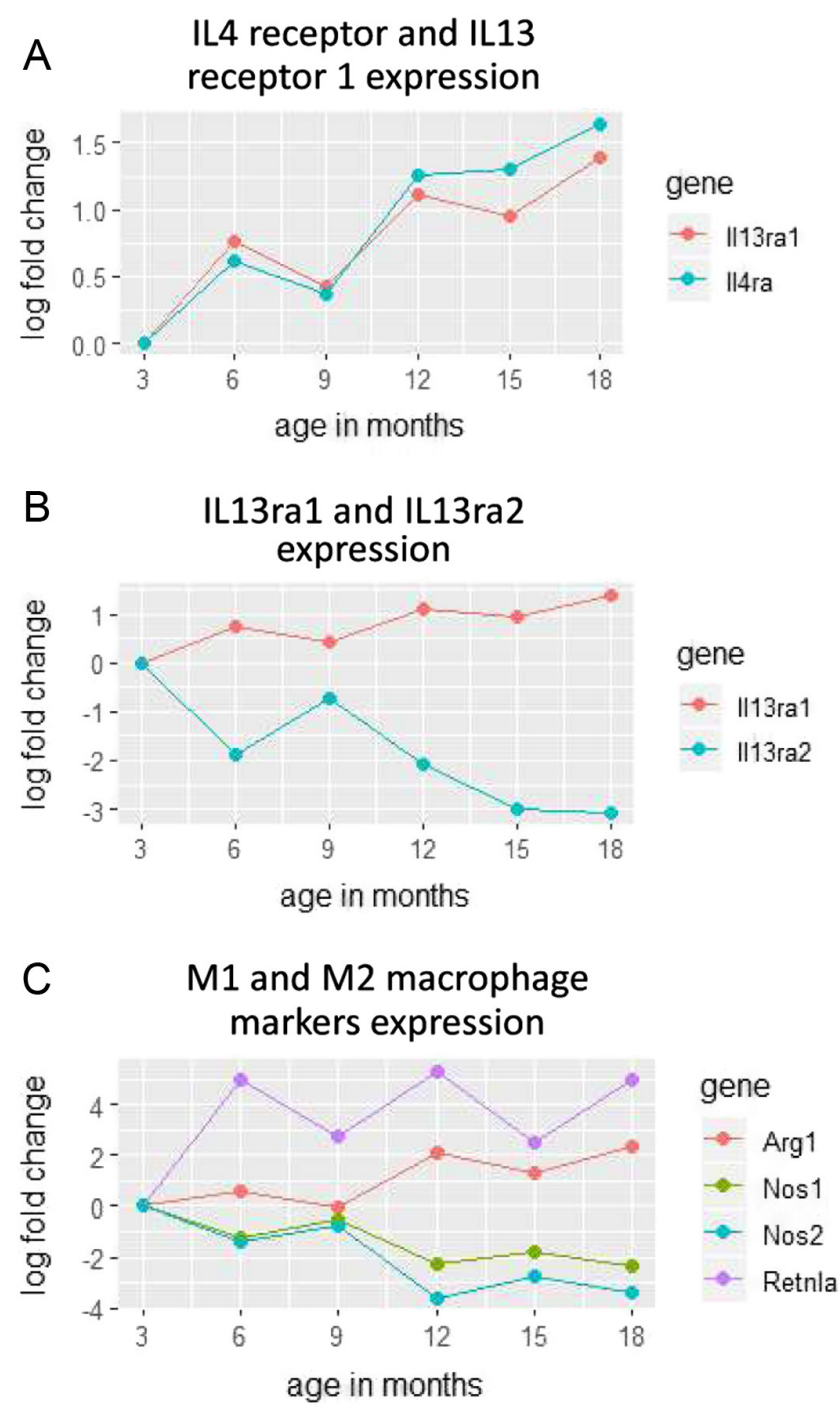

Figure 4 The expression pattern of genes associated with type 2 inflammation over the course of ovarian aging. The data points correspond to the average log fold change of the normalized read counts of the gene at each time point compared to that at 3 months. (A) The expression change of IL4 receptor (II $4 \mathrm{ra}$, blue, $\mathrm{p}=1.77 \mathrm{e}-11$ ) and IL13 receptor 1 (II13ra1, red, $P=2.54 \mathrm{e}-7$ ) in the ovarian tissue over the six time points. (B) The expression change of IL13 receptor 1 (II13ra1, red) and IL13 receptor 2 (II13ra2, blue, $P=1.78 \mathrm{e}-7$ ) in the ovarian tissue over the six time points. (C) The expression change of M1 macrophage markers nitric oxide synthase 1 (Nos1, green, $P=1.01 \mathrm{e}-6$ ) and 2 (Nos2, blue, $P=9.73 \mathrm{e}-8$ ), and M2 macrophage markers arginase 1 (Arg1, red, $P=0.0016)$ and Retnla (gene that encode RELM- $\alpha$, purple, $P=0.093$ ) in the ovarian tissue over the six time points.

precursor cells and migrate into different tissues during embryogenesis are known as tissue residentmacrophages, while those that derive from blood monocytes that infiltrate tissues after birth are known as monocytederived macrophages (Lavin et al. 2015, Zhao et al. 2018). We used Ly6C as a marker for monocyte-derived macrophages (Lagasse \& Weissman 1996). According to our flow cytometry analysis, we observed two populations of ovarian macrophages expressing different levels of Ly6C, indicating the presence of both resident (Ly6C $\mathrm{C}^{-}$) and monocyte-derived $\left(\mathrm{Ly} 6 \mathrm{C}^{+}\right)$macrophages in the mouse ovary. Both types of macrophages are found in both the young and old mouse ovary. Strikingly, the proportion of $\mathrm{Ly}_{6} \mathrm{C}^{+}$macrophages (monocyte-derived) among all ovarian macrophages increased drastically from $14.5 \pm 6.05 \%$ in the young ovaries to $59.9 \pm 9.52 \%$ in the aged ovaries (Fig. 6A) $(P=0.0011)$. In contrast, the proportion of Ly6C- macrophages (tissue resident) decreased significantly from $84.8 \pm 5.4 \%$ in the young ovaries to $37.7 \pm 11.3 \%$ in the aged ovaries (Fig. 6A) $(P=0.0014)$. This finding suggests a fundamental shift in the main source of ovarian macrophages over the course of aging. We then used the coexpression of Ly6C, CD64, $\mathrm{CD} 11 \mathrm{~b}$ and $\mathrm{CD} 45$ as a signature and examined the presence of monocytes (Fig. 5A) in the young and old ovaries. In line with the aging-associated increase in the monocyte-derived macrophages, we observed a marked increase in the proportion of monocytes among myeloid cells in the old ovaries (Fig. 6B) $(P=0.007)$.

We speculated that the elevated ratio of monocytederived to tissue resident macrophages in the aged ovary could be the consequence of an increased recruitment of monocytes. Indeed, our RNAseq data reflects a significant increase in the expression level of the chemokines (including $\mathrm{Ccl} 2, \mathrm{Ccl} 3, \mathrm{Ccl} 5, \mathrm{Ccl} 7$, and Ccl12) that are responsible for monocyte recruitment (Shi \& Pamer 2011) in the 15 months old ovaries compared to that in 3 months old ovaries (Fig. 6C), which suggests a growing level of monocyte recruitment in the ovarian tissue during aging.

In addition to recruitment, both monocyte-derived and tissue resident macrophages are capable of maintaining their populations through proliferation in situ at steady state or during inflammation (Jenkins et al. 2011, Italiani \& Boraschi 2014). Thus, alterations in the cell proliferation activity may also contribute to the changes in the macrophage population. To explore this possibility, we examined the expression of proliferation marker Ki67 (a protein expressed in cells that are not in G0 phase) (Huang et al. 2018) in macrophages in the young and old ovaries. Since the number of ovarian macrophages is significantly lower in the old ovaries, we expected to observe an aging-associated decrease in the Ki67 expression. Indeed, compared to that in young ovaries, there is a marked reduction of $\mathrm{Ki} 67^{+}$cells among the entire macrophage population in the old ovaries $(22.9 \pm 2.8 \%$ in young ovaries and $17.1 \pm 1.7 \%$ in old ovaries, $P=0.0175$ ) (Fig. 6D). Interestingly, the percentage of $\mathrm{Ki} 67^{+}$cells reduced significantly in Ly6 $\mathrm{C}^{+}$monocyte-derived macrophages $(P=0.0208)$ but not in tissue resident macrophages $(P=0.172)$ in old ovaries (Fig. 6D). This finding suggests that the ability of ovarian macrophages to self-renew through proliferation likely reduces in general over the course of aging, and the increase in the proportion of monocyte-derived 


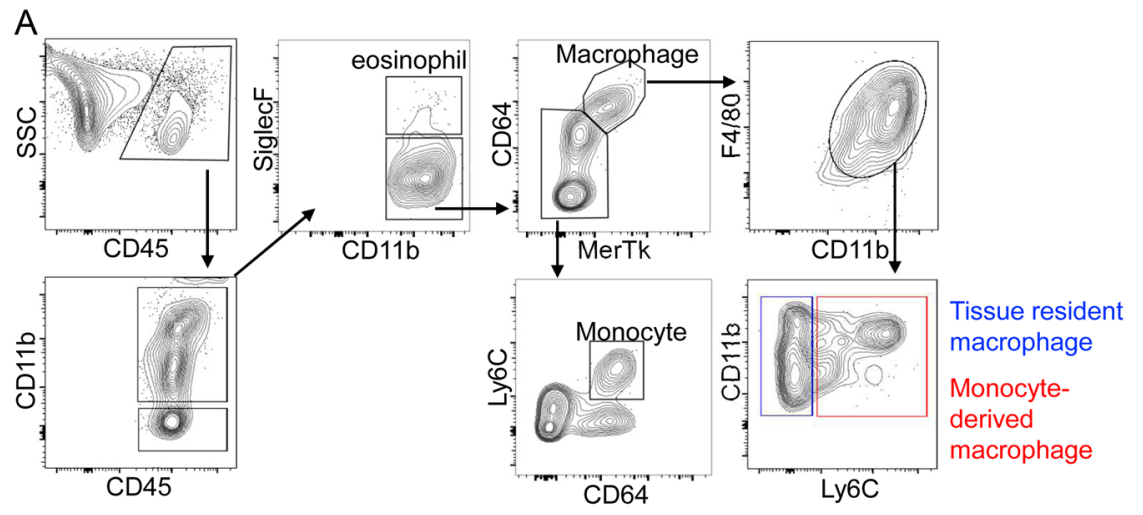

B

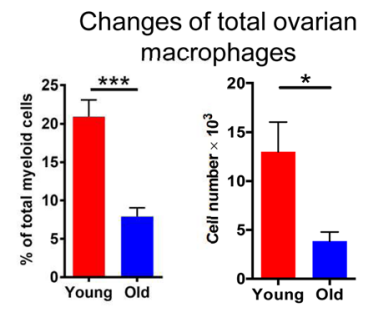

D Changes of ovarian M1 macrophage (MHCII)
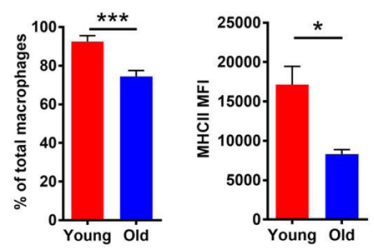

macrophages among ovarian macrophages may attribute to enhanced monocyte recruitment in old ovaries.

Together, our results show that, over the course of aging, the ovarian macrophage number declines and the proportion of $\mathrm{M} 2$-like macrophages increases in the macrophage pool in the ovary. Furthermore, macrophage proliferation decreases in general along with the increased percentage of monocyte-derived macrophages, indicating a shifted macrophage ontogeny in the aged ovary. These data suggest that the tissue microenvironment in the aged ovary modulates macrophage dynamics and phenotypes which may in turn contribute to inflammaging.

\section{Ovarian aging is accompanied by the expansion of eosinophils}

The potential elevation of IL4 and IL13 signaling activity and the increased proportion of M2 macrophages during ovarian aging are both signatures of elevated type 2 inflammation (Mills et al. 2000, Allen \& Wynn 2011). We thus examined the presence of eosinophils, which is another type of immune cell essential for type 2 inflammation (Allen \& Wynn 2011) and capable of producing IL4 and IL13 (Goh et al. 2013, Heredia et al. 2013, Huang \& Appleton 2016). Using flow cytometry, we identified eosinophils
Figure 5 The aging-associated shift in macrophage polarization in the ovarian tissue. (A) Gating strategy for the characterization of the ovarian macrophage populations. (B) The change of total ovarian macrophages during aging. The bar charts reflect the percentage of ovarian myeloid cells (CD11 b+ and CD45 $\left.{ }^{+}\right)$ that are macrophages in young (red, $n=3$ ) and old (blue, $n=3$ ) ovaries $(P=0.0004)$, as well as the number of total ovarian macrophages in young $(n=3)$ and old $(n=3)$ ovaries $(P=0.0226)$. (C) The change of alternatively activated (M2) ovarian macrophages over the course of aging. The bar charts reflect the percentage of total ovarian macrophages that are alternatively activated $\left(\operatorname{RELM}-\alpha^{+}\right)$in young $(n=3)$ and old $(n=3)$ ovaries $(P=0.0329)$, and the median fluorescence intensity (MFI) of RELM- $\alpha$ signal in young $(n=3)$ and old $(n=3)$ ovaries $(P=0.059)$. (D) The change of classically activated (M1) ovarian macrophages over the course of aging. The bar charts reflect the percentage of total ovarian macrophages that are classically activated $\left(\mathrm{MHCII}^{+}\right)$in young $(n=3)$ and old $(n=3)$ ovaries $(P=0.001)$, and the MFI of MHCII signal in young $(n=3)$ and old $(n=3)$ ovaries $(P=0.0101)$. Mean \pm S.D. are shown in the column bar graph. $P$ values were calculated using unpaired Student's $t$ test was used for all statistical analysis in this figure. $n=3$. All experiments were repeated two times with ovaries from 3-month-old (young) and 15-month-old (old) mice. based on the co-expression of Siglec-F, CD11b and CD45 (Wu et al. 2011) (Fig. 7A). Intriguingly, the number of Siglec- $\mathrm{F}^{+}, \mathrm{CD} 11 \mathrm{~b}^{+}$and $\mathrm{CD} 45^{+}$cells increased significantly in old ovaries compared to that in young ovaries $(P=0.0153)$ (Fig. 7A and B). In line with this result, the percentage of Siglec- $\mathrm{F}^{+} \mathrm{CD} 11 \mathrm{~b}^{+}$and $\mathrm{CD}^{2} 5^{+}$cells among all myeloid cells also show a strong increasing trend in old ovaries though the change is not significant $(P=0.06)$ (Fig. 7B). Consistent with an increased eosinophil number, our RNAseq data revealed an increased expression of various eosinophil recruiting chemokines including $\mathrm{Ccl} 3$, Ccl5, Ccl7, Ccl8 and Ccl12 in the old ovaries (Fig. 6C) (Rosenberg et al. 2013). Thus, our findings suggest that ovarian aging may be accompanied by an enhancement of eosinophil recruitment, which may contribute to the elevation of IL4 and IL13 signaling, and therefore the increased M2 polarization of ovarian macrophages.

\section{Discussion}

In recent decades, research evidence has established an increasingly strong connection between aberrant immune function, inflammatory tissue environment, and many aging-related pathologies. Elucidating the nature and progression of aging-associated changes 

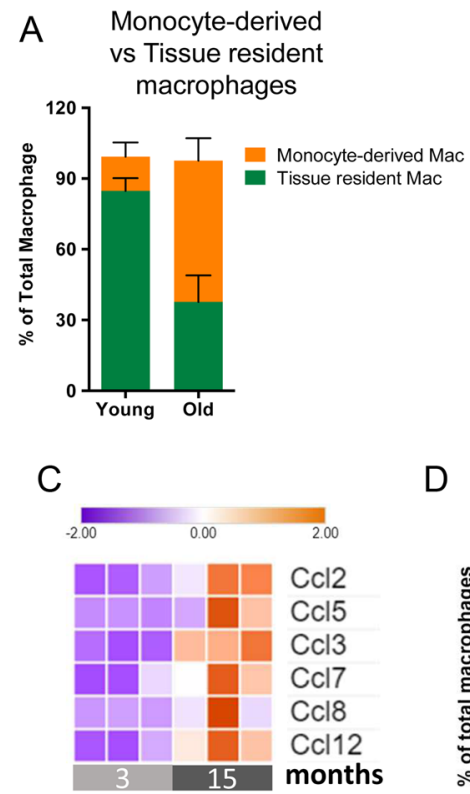
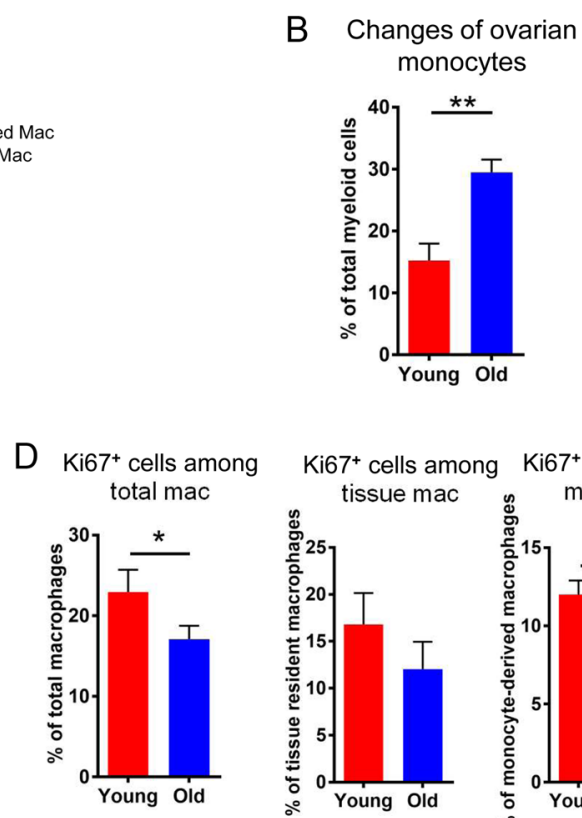

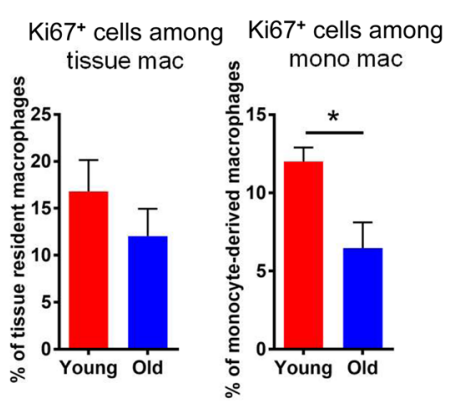

Figure 6 The aging-associated shift in macrophage ontogeny in the ovarian tissue. (A) The aging-associated changes in the percentage of ovarian macrophages that are monocyte-derived (orange) or tissue resident (green), ovaries from three young and three old animals were used for the assay. For changes in the percentage of monocytederived macrophages among total macrophages, $P=0.0011$. For changes in the percentage of tissue resident macrophages among total macrophages, $P=0.0014$. (B) Percentage of myeloid cells $\left(\mathrm{CD} 11^{+}\right.$and $\mathrm{CD}_{4} 5^{+}$that are monocytes (Ly6C ${ }^{+}$and $\left.\mathrm{CD}_{64}{ }^{+}\right)$ in young $(n=3)$ and old $(n=3)$ ovaries $(P=0.007)$. (C) The changes in the transcript levels of chemokines that are associated with monocyte/eosinophil recruitment in young (3 months) and old (15 months) ovaries. The heatmap is constructed based on the normalized read counts from the RNAseq dataset, which can be found in Supplementary Table 1. (D) The percentage of total ovarian macrophages $(P=0.0175)$, tissue resident macrophages $(P=0.172)$, or monocyte-derived macrophages $(P=0.0208)$ that are $\mathrm{Ki} 67^{+}$in young (red) and old (blue) ovaries. Mean \pm S.D. are shown in the column bar graph. $P$ values were calculated using unpaired Student's $t$ test was used for all statistical analysis of the flow cytometry results in this figure. $n=3$. All experiments were repeated two times with ovaries from 3-month-old (young) and 15-month-old (old) mice. in immune activities in different tissues and how the altered immunity influences the tissue homeostasis thus represent an important aspect of the betterment of our understanding of the aging process.

In this study, we provided a detailed atlas of the transcriptomic changes that take place in the mouse ovary over the course of aging and showed that ovarian aging is associated with a drastic upregulation of genes involved in both adaptive and innate immunity. The rise of innate immune activity is consistent with the development of chronic inflammation during aging. But the elevation of adaptive immunity is quite interesting, since the aging-related inflammatory response is sterile inflammation without the involvement of pathogens (Fulop et al. 2017), and the production of naïve T cells is known to decline during aging (Salam et al. 2013). Interestingly, in recent years, research evidence revealed the presence of tissue-resident memory T cells (Trm), a subpopulation of $\mathrm{T}$ cells that reside in different tissues and mediate rapid pathogen killing upon infection (Mueller \& Mackay 2016, Kumar et al. 2018). This group of $\mathrm{T}$ cells is known to accumulate in tissues over time in compensation for the decline of naïve T cells (Saule et al. 2006) even in absence of an active infection. It is possible that the rise of Trm cells in the ovarian tissue is responsible for the aging-associated expression upregulation of $\mathrm{T}$ cell-related genes.

More intriguingly, the terms associated with elevated inflammation and innate immunity are also enriched among genes upregulated in the aged ovaries, consistent with the development of inflammaging. We further examined the changes of genes associated with inflammation and showed that IL4 and IL13 signaling, a hallmark of type 2 immunity elevates and the expression of M2 macrophage signature genes increase over the course of aging. Consistent with that, our flow cytometry results indicate that $\mathrm{M} 2$ polarization indeed becomes more prevalent among the macrophages in the old ovary, while M1 polarization shows marked decline. Interestingly, similar aging-related shifts in macrophage plasticity have also been observed in mouse retinal tissue (Cruz-Guilloty et al. 2013). M2 macrophages activated by IL4 and IL13 produce proline, which is a critical building block of collagen (Wynn \& Vannella 2016). Thus, we speculated that the shifted macrophage plasticity and elevated type 2 immunity as well as M2 macrophage activities contribute to the development of fibrosis in the ovary during aging. However, it is necessary to note that the characterization of $M 1$ and $M 2$ macrophages is largely based on in vitro cultures in the presence of IFN- $\gamma$ or IL4/IL13. The complexity of macrophages is reflected 


\section{A Ovarian eosinophils}

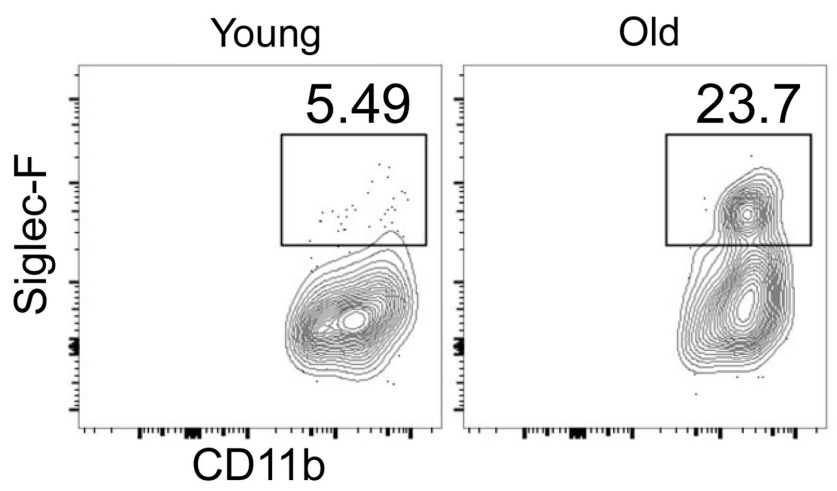

\section{B \\ Changes of ovarian eosinophils}
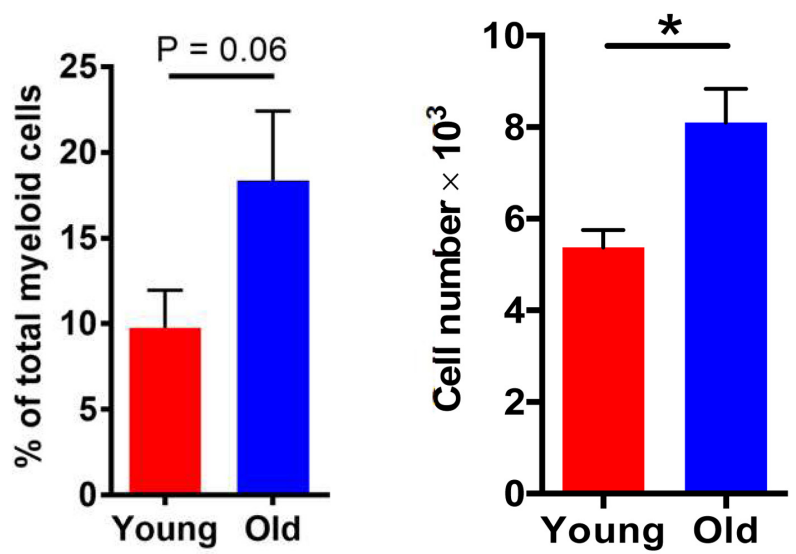

Figure 7 The aging-associated changes in ovarian eosinophils. (A) The characterization of eosinophils in young and old ovaries. For the better demonstration of the aging-associated eosinophil population changes, one representative flow cytometry plot of the three replicates from each age groups were included. The numbers above the gate indicate the percentage of the gated population among total cells on the chart. (B) The differences in the percentage of eosinophils in total myeloid cells $(P=0.06)$, and the numbers of eosinophils $(P=0.0153)$, in young $(n=3)$ and old $(n=3)$ ovaries. Mean \pm S.D, are shown in the column bar graph. $P$ values were calculated using unpaired Student's $t$ test for the statistical analysis of the flow cytometry results in this figure. $n=3$. All experiments were repeated two times with ovaries from 3-month-old (young) and 15-month-old (old) mice.

by their origins, locations, heterogeneous phenotypes and metabolism, all of which govern the functions of these cells in various tissues under homeostatic and inflammatory conditions. Our results provide important insights on the altered dynamics of macrophages in the aged mouse ovary. Macrophages have been shown to play functional roles in the mammalian ovary, including the regulation of corpus luteum development and vascularization (Turner et al. 2011, Care et al. 2013), cell proliferation and follicular growth (Fukumatsu et al. 1992, Richards et al. 2002). Therefore, further investigation of the impact of changing macrophage populations on the ovarian functions will establish an intriguing link between inflammaging and deterioration of reproductive potential over the course of aging.

Furthermore, our results also revealed an increased number of eosinophils in the aged ovary. Eosinophils are capable of producing a panel of type 2 cytokines, including IL4 and IL13 in various tissues, and have been linked to regenerative responses to tissue injury (Goh et al. 2013, Heredia et al. 2013, Huang \& Appleton 2016). Notably, eosinophils have been shown to promote alternative activation of tissue macrophages directly via the production of IL4, which are required for increasing systemic insulin sensitivity (Goh et al. 2013). These observations demonstrated that eosinophils contribute to tissue homeostasis and repair. Since the mammalian ovary experiences regular cycles of ovulations, which bear resemblance to the wounding and healing process, the increased number of eosinophils could be the consequence in response to tissue damages that occur during ovulation. Thus, the roles of eosinophils in ovarian function and whether they impact the phenotype of ovarian macrophages during aging merit further studies.

We observed a decline of Ki67 expressing cells in ovarian macrophages in the aged ovary, indicating an impairment of macrophage proliferation at old age. Indeed, the total macrophage number exhibits a significant reduction in the 15 months old ovary. Local macrophage proliferation has been shown to be regulated by various signals, such as IL4 (Jenkins et al. 2013) and colony-stimulating factor 1 (CSF-1) (Yu et al. 2012). However, our RNA-seq analysis reveals hallmarks of an aging-associated enhanced type 2 immune response including elevated I/4ra expression. Thus, it is unlikely that changes in IL4 signaling is involved in the reduced proliferation of ovarian macrophages. Alternatively, macrophages are shown to undergo proliferation in vivo upon exposure to estrogen, an essential hormone for female reproduction (Pepe et al. 2017, 2018). Since estrogen production declines over the course of reproductive aging (Van Kempen et al. 2011, Daniel 2013), the impaired ovarian macrophage proliferation may be due to the diminishing production of estrogen during aging. In summary, our finding implies that restoring the ovarian macrophage pool by enhancing macrophage replicating activity and harnessing macrophage polarization which in turn improves ovarian functions can be a potentially promising therapeutic strategy.

Our results also show that the composition of the ovarian macrophage population goes through changes during aging, as the percentage of monocyte-derived macrophages significantly increases during aging and becomes more dominant in the ovarian macrophage pool. Since monocytes are actively recruited to tissues by chemotaxis during inflammation and are more prone to polarization into M1 macrophages, it is possible that the perturbed balance between monocyte-derived and tissue resident macrophages contributes to the shift in 
macrophage polarization in the aged ovary. Moreover, although the lifespan of ovarian macrophages remains unknown, others have indicated that the lifespan of tissue resident macrophages ranges from months to years (Parihar et al. 2010, Hashimoto et al. 2013). A complex network of survival and death signals determines the lifespan of both monocytes and macrophages (Parihar et al. 2010). Thus, we speculate that the increased apoptosis in tissue resident macrophages in the aged ovary may also contribute to the altered ontogeny of ovarian macrophages and further influences of the physiology of the ovary.

Given that rampant cytokine production and fibrotic tissue environment can be pathogenic and harmful for oocyte development, it will be important in the future to understand the underlying mechanisms of the aging associated changes in the macrophage population. Similar to that in human, reproductive aging is associated with severe impairment of fertility in female mice, as their estrous cycles become increasingly irregular and eventually cease all together at old age (Nelson et al. 1982). The underlying causes of this aging-related loss of fertility are thought to be a combined effect of the depletion of ovarian follicle reserve, which is a production center of estrogens, and the reduced sensitivity of Gonadotropinreleasing-hormone $(\mathrm{GnRH})$ expressing neurons to neuropeptides (Wise et al. 2002). This disruption of the estrous cycle is accompanied by deregulation of estrogen signaling, as the hormonal activity loses its cyclic pattern together with the gradual loss of estrous cycles. Since immune cells, including macrophages, are known to express estrogen receptors (Lambert et al. 2004), and are strongly influenced by estrogen signaling, it is possible that the alterations in estrogen signaling at advanced reproductive age contributes to the alterations in ovarian macrophage functions. Other research has shown that hypoxia, another common aging-related condition, also impacts macrophage polarization and activities (Raggi et al. 2017). Further studies will be necessary to determine which of these mechanisms is responsible for the alteration of macrophage populations in the ovary during aging.

Inflammaging is a complex phenomenon of low grade and chronic inflammation that results from genetic, epigenetic and metabolic dysfunction in different cell types and organs. More recently, many others factors have been linked to inflammaging locally and systemically, including altered gut microbiota, persistent senescent cells and dysregulated mitochondria (Franceschi \& Campisi 2014, Franceschi et al. 2017). Understanding these factors along with functions of macrophages will shed light on novel antiaging strategies to mitigate agerelated changes of the ovarian tissue environment.

\section{Supplementary materials}

This is linked to the online version of the paper at https://doi. org/10.1530/REP-19-0330.

\section{Declaration of interest}

The authors declare that there is no conflict of interest that could be perceived as prejudicing the impartiality of the research reported.

\section{Funding}

This work was funded by grants to $\mathrm{L}$ B from $\mathrm{NIH}$ 4K12HD00084929 awarded to the Reproductive Scientist Development Program by the Eunice Kennedy Shriver National Institute of Child Health \& Human Development and the American Board of Obstetrics \& Gynecology, the National Institute of General Medical Sciences P20 GM121298-01, and the Connie Howes Award from Women and Infants Hospital of Rhode Island.

\section{Author contribution statement}

Z Z designed, planned and executed the experiments, participated in the data analysis, established the collaborations, and wrote the manuscript. F S analyzed data and participated in the manuscript preparation. L $\mathrm{H}$ designed and executed experiments and participated in the writing of the manuscript. $\mathrm{H} \mathrm{C}$ participated in the execution of the experiments and the preparation of the manuscript. L B designed and supervised the experiments and reviewed manuscript.

\section{Acknowledgments}

The authors thank Dr John Sedivy for kindly providing us with the ovaries used for this study. We would also like thank Bianca Kun, Dr Anna Petrashen, Dr Jill Kreiling, and Amy Elias for their indispensable roles in helping to coordinate the ovary harvesting. We thank Xiaotian Wu for his valuable input and suggestions in the RNAseq data analysis. They thank Dr Gary Wessel for his advice on this project.

\section{References}

Allen JE \& Wynn TA 2011 Evolution of Th2 immunity: a rapid repair response to tissue destructive pathogens. PLoS Pathogens 7 e1002003. (https://doi.org/10.1371/journal.ppat.1002003)

Banerjee J, Sharma R, Agarwal A, Maitra D, Diamond MP \& Abu-Soud HM 2012 IL-6 and mouse oocyte spindle. PLoS ONE 7 e35535. (https://doi. org/10.1371/journal.pone.0035535)

Briley SM, Jasti S, Mccracken JM, Hornick JE, Fegley B, Pritchard MT \& Duncan FE 2016 Reproductive age-associated fibrosis in the stroma of the mammalian ovary. Reproduction 152 245-260. (https://doi. org/10.1530/REP-16-0129)

Care AS, Diener KR, Jasper MJ, Brown HM, Ingman WV \& Robertson SA 2013 Macrophages regulate corpus luteum development during embryo implantation in mice. Journal of Clinical Investigation 123 3472-3487. (https://doi.org/10.1172/JCl60561)

Chavez-Galan L, Olleros ML, Vesin D \& Garcia I 2015 Much more than M1 and M2 macrophages, there are also CD169(+) and TCR(+) macrophages. Frontiers in Immunology 6 263. (https://doi.org/10.3389/ fimmu.2015.00263)

Cheng H, Wang Z, Fu L \& Xu T 2019 Macrophage polarization in the development and progression of ovarian cancers: an overview. Frontiers in Oncology 9 421. (https://doi.org/10.3389/fonc.2019.00421)

Chiang T, Duncan FE, Schindler K, Schultz RM \& Lampson MA 2010 Evidence that weakened centromere cohesion is a leading cause of age- 
related aneuploidy in oocytes. Current Biology 20 1522-1528. (https:// doi.org/10.1016/j.cub.2010.06.069)

Colotta F, Allavena P, Sica A, Garlanda C \& Mantovani A 2009 Cancer-related inflammation, the seventh hallmark of cancer: links to genetic instability. Carcinogenesis 30 1073-1081. (https://doi.org/10.1093/carcin/bgp127)

Cruz-Guilloty F, Saeed AM, Echegaray IJ, Duffort S, Ballmick A, Tan Y, Betancourt M, Viteri E, Ramkhellawan GC, Ewald E et al. 2013 Infiltration of proinflammatory $\mathrm{m} 1$ macrophages into the outer retina precedes damage in a mouse model of age-related macular degeneration. International Journal of Inflammation 2013 503725. (https://doi.org/10.1155/2013/503725)

Daniel JM 2013 Estrogens, estrogen receptors, and female cognitive aging: the impact of timing. Hormones and Behavior 63 231-237. (https://doi. org/10.1016/j.yhbeh.2012.05.003)

Doherty TM, Kastelein R, Menon S, Andrade S \& Coffman RL 1993 Modulation of murine macrophage function by IL-13. Journal of Immunology 151 7151-7160.

Doyle AG, Herbein G, Montaner LJ, Minty AJ, Caput D, Ferrara P \& Gordon S 1994 Interleukin-13 alters the activation state of murine macrophages in vitro: comparison with interleukin-4 and interferongamma. European Journal of Immunology 24 1441-1445. (https://doi. org/10.1002/eji.1830240630)

Duncan FE, Jasti S, Paulson A, Kelsh JM, Fegley B \& Gerton JL 2017 Age-associated dysregulation of protein metabolism in the mammalian oocyte. Aging Cell 16 1381-1393. (https://doi.org/10.1111/acel.12676)

Eastman AJ, He X, Qiu Y, Davis MJ, Vedula P, Lyons DM, Park YD, Hardison SE, Malachowski AN, Osterholzer JJ et al. 2015 Cryptococcal heat shock protein 70 homolog Ssa1 contributes to pulmonary expansion of Cryptococcus neoformans during the afferent phase of the immune response by promoting macrophage M2 polarization. Journal of Immunology 194 5999-6010. (https://doi.org/10.4049/jimmunol.1402719)

Efron B \& Tibshirani R 2007 On testing the significance of sets of genes. Annals of Applied Statistics 1 107-129. (https://doi.org/10.1214/07AOAS101)

Ferrucci L, Corsi A, Lauretani F, Bandinelli S, Bartali B, Taub DD, Guralnik JM \& Longo DL 2005 The origins of age-related proinflammatory state. Blood 105 2294-2299. (https://doi.org/10.1182/blood-2004-07-2599)

Franceschi C \& Campisi J 2014 Chronic inflammation (inflammaging) and its potential contribution to age-associated diseases. Journals of Gerontology 69 (Supplement 1) S4-S9. (https://doi.org/10.1093/gerona/ glu057)

Franceschi C, Garagnani P, Vitale G, Capri M \& Salvioli S 2017 Inflammaging and 'garb-aging'. Trends in Endocrinology and Metabolism 28 199-212. (https://doi.org/10.1016/j.tem.2016.09.005)

Fukumatsu Y, Katabuchi H, Naito M, Takeya M, Takahashi K \& Okamura H 1992 Effect of macrophages on proliferation of granulosa cells in the ovary in rats. Journal of Reproduction and Fertility 96 241-249. (https:// doi.org/10.1530/jrf.0.0960241)

Fulop T, Larbi A, Dupuis G, Le Page A, Frost EH, Cohen AA, Witkowski JM \& Franceschi C 2017 Immunosenescence and inflamm-aging as two sides of the same coin: friends or foes? Frontiers in Immunology 81960. (https://doi.org/10.3389/fimmu.2017.01960)

Gautier EL, Shay T, Miller J, Greter M, Jakubzick C, Ivanov S, Helft J, Chow A, Elpek KG, Gordonov S et al. 2012 Gene-expression profiles and transcriptional regulatory pathways that underlie the identity and diversity of mouse tissue macrophages. Nature Immunology 13 1118-1128. (https://doi.org/10.1038/ni.2419)

Ge J, Li C, Li C, Huang Z, Zeng J, Han L \& Wang Q 2019 SIRT6 participates in the quality control of aged oocytes via modulating telomere function. Aging 11 1965-1976. (https://doi.org/10.18632/aging.101885)

Germano G, Allavena P \& Mantovani A 2008 Cytokines as a key component of cancer-related inflammation. Cytokine 43 374-379. (https://doi.org/10.1016/j.cyto.2008.07.014)

Goh YP, Henderson NC, Heredia JE, Red Eagle A, Odegaard JI, Lehwald N, Nguyen KD, Sheppard D, Mukundan L, Locksley RM et al. 2013 Eosinophils secrete IL-4 to facilitate liver regeneration. PNAS $\mathbf{1 1 0}$ 9914-9919. (https://doi.org/10.1073/pnas.1304046110)

Gordon S \& Taylor PR 2005 Monocyte and macrophage heterogeneity. Nature Reviews: Immunology 5 953-964. (https://doi.org/10.1038/nri1733)

Grondahl ML, Yding Andersen C, Bogstad J, Nielsen FC, Meinertz H \& Borup R 2010 Gene expression profiles of single human mature oocytes in relation to age. Human Reproduction 25 957-968. (https://doi. org/10.1093/humrep/deq014)
Hashimoto D, Chow A, Noizat C, Teo P, Beasley MB, Leboeuf M, Becker CD, See P, Price J, Lucas D et al. 2013 Tissue-resident macrophages self-maintain locally throughout adult life with minimal contribution from circulating monocytes. Immunity $\mathbf{3 8}$ 792-804. (https:// doi.org/10.1016/j.immuni.2013.04.004)

Heffner LJ 2004 Advanced maternal age--how old is too old? New England Journal of Medicine 351 1927-1929. (https://doi.org/10.1056/ NEJMp048087)

Heredia JE, Mukundan L, Chen FM, Mueller AA, Deo RC, Locksley RM, Rando TA \& Chawla A 2013 Type 2 innate signals stimulate fibro/ adipogenic progenitors to facilitate muscle regeneration. Cell $\mathbf{1 5 3}$ 376-388. (https://doi.org/10.1016/j.cell.2013.02.053)

Hornick JE, Duncan FE, Sun M, Kawamura R, Marko JF \& Woodruff TK 2015 Age-associated alterations in the micromechanical properties of chromosomes in the mammalian egg. Journal of Assisted Reproduction and Genetics 32 765-769. (https://doi.org/10.1007/s10815-015-0453-y)

Huang L \& Appleton JA 2016 Eosinophils in helminth infection: defenders and dupes. Trends in Parasitology 32 798-807. (https://doi.org/10.1016/j. pt.2016.05.004)

Huang L, Nazarova EV, Tan S, Liu Y \& Russell DG 2018 Growth of Mycobacterium tuberculosis in vivo segregates with host macrophage metabolism and ontogeny. Journal of Experimental Medicine 215 1135-1152. (https://doi.org/10.1084/jem.20172020)

Italiani P \& Boraschi D 2014 From monocytes to M1/M2 macrophages: phenotypical vs. functional differentiation. Frontiers in Immunology $\mathbf{5}$ 514. (https://doi.org/10.3389/fimmu.2014.00514)

Jenkins SJ, Ruckerl D, Cook PC, Jones LH, Finkelman FD, Van Rooijen N, Macdonald AS \& Allen JE 2011 Local macrophage proliferation, rather than recruitment from the blood, is a signature of TH2 inflammation. Science 332 1284-1288. (https://doi.org/10.1126/science.1204351)

Jenkins SJ, Ruckerl D, Thomas GD, Hewitson JP, Duncan S, Brombacher F, Maizels RM, Hume DA \& Allen JE 2013 IL-4 directly signals tissueresident macrophages to proliferate beyond homeostatic levels controlled by CSF-1. Journal of Experimental Medicine 210 2477-2491. (https://doi.org/10.1084/jem.20121999)

Johnson JA \& Tough S 2017 No-271-delayed child-bearing. Journal of Obstetrics and Gynaecology Canada 39 e500-e515. (https://doi. org/10.1016/j.jogc.2017.09.007)

Jones KT \& Lane SI 2013 Molecular causes of aneuploidy in mammalian eggs. Development 140 3719-3730. (https://doi.org/10.1242/ dev.090589)

Kennedy BK, Berger SL, Brunet A, Campisi J, Cuervo AM, Epel ES, Franceschi C, Lithgow GJ, Morimoto RI, Pessin JE et al. 2014 Geroscience: linking aging to chronic disease. Cell 159 709-713. (https://doi.org/10.1016/j.cell.2014.10.039)

Kumar BV, Connors TJ \& Farber DL 2018 Human T cell development, localization, and function throughout life. Immunity 48 202-213. (https://doi.org/10.1016/j.immuni.2018.01.007)

Lagasse E \& Weissman IL 1996 Flow cytometric identification of murine neutrophils and monocytes. Journal of Immunological Methods 197 139-150. (https://doi.org/10.1016/0022-1759(96)00138-x)

Lambert KC, Curran EM, Judy BM, Lubahn DB \& Estes DM 2004 Estrogen receptor-alpha deficiency promotes increased TNF-alpha secretion and bacterial killing by murine macrophages in response to microbial stimuli in vitro. Journal of Leukocyte Biology 75 1166-1172. (https://doi. org/10.1189/jlb.1103589)

Lavin Y, Mortha A, Rahman A \& Merad M 2015 Regulation of macrophage development and function in peripheral tissues. Nature Reviews: Immunology 15 731-744. (https://doi.org/10.1038/nri3920)

Love MI, Huber W \& Anders S 2014 Moderated estimation of fold change and dispersion for RNA-seq data with DESeq2. Genome Biology 15550. (https://doi.org/10.1186/s13059-014-0550-8)

Lupardus PJ, Birnbaum ME \& Garcia KC 2010 Molecular basis for shared cytokine recognition revealed in the structure of an unusually high affinity complex between IL-13 and IL-13Ralpha2. Structure 18 332-342. (https://doi.org/10.1016/j.str.2010.01.003)

Mantovani A, Allavena P, Sica A \& Balkwill F 2008 Cancer-related inflammation. Nature 454 436-444. (https://doi.org/10.1038/ nature07205)

Mi H, Huang X, Muruganujan A, Tang H, Mills C, Kang D \& Thomas PD 2017 PANTHER version 11: expanded annotation data from gene ontology and reactome pathways, and data analysis tool enhancements. 
Nucleic Acids Research 45 D183-D189. (https://doi.org/10.1093/nar/ gkw1138)

Mi H, Muruganujan A, Ebert D, Huang X \& Thomas PD 2019 PANTHER version 14: more genomes, a new PANTHER GO-slim and improvements in enrichment analysis tools. Nucleic Acids Research 47 D419-D426. (https://doi.org/10.1093/nar/gky1038)

Mills CD, Kincaid K, Alt JM, Heilman MJ \& Hill AM 2000 M-1/M-2 macrophages and the Th1/Th2 paradigm. Journal of Immunology $\mathbf{1 6 4}$ 6166-6173. (https://doi.org/10.4049/jimmunol.164.12.6166)

Moley KH \& Schreiber JR 1995 Ovarian follicular growth, ovulation and atresia. Endocrine, paracrine and autocrine regulation. Advances in Experimental Medicine and Biology 377 103-119. (https://doi. org/10.1007/978-1-4899-0952-7_7)

Mueller SN \& Mackay LK 2016 Tissue-resident memory T cells: local specialists in immune defence. Nature Reviews: Immunology 16 79-89. (https://doi.org/10.1038/nri.2015.3)

Nelson JF, Felicio LS, Randall PK, Sims C \& Finch CE 1982 A longitudinal study of estrous cyclicity in aging C57BL/6J mice: I. Cycle frequency, length and vaginal cytology. Biology of Reproduction 27 327-339. (https://doi.org/10.1095/biolreprod27.2.327)

Nteeba J, Ganesan S \& Keating AF 2014 Progressive obesity alters ovarian folliculogenesis with impacts on pro-inflammatory and steroidogenic signaling in female mice. Biology of Reproduction 91 86. (https://doi. org/10.1095/biolreprod.114.121343)

Parihar A, Eubank TD \& Doseff AI 2010 Monocytes and macrophages regulate immunity through dynamic networks of survival and cell death. Journal of Innate Immunity 2 204-215. (https://doi. org/10.1159/000296507)

Pepe G, Braga D, Renzi TA, Villa A, Bolego C, D'avila F, Barlassina C, Maggi A, Locati M \& Vegeto E 2017 Self-renewal and phenotypic conversion are the main physiological responses of macrophages to the endogenous estrogen surge. Scientific Reports 7 44270. (https://doi. org/10.1038/srep44270)

Pepe G, Locati M, Della Torre S, Mornata F, Cignarella A, Maggi A \& Vegeto E 2018 The estrogen-macrophage interplay in the homeostasis of the female reproductive tract. Human Reproduction Update $\mathbf{2 4}$ 652-672. (https://doi.org/10.1093/humupd/dmy026)

Pine GM, Batugedara HM \& Nair MG 2018 Here, there and everywhere: resistin-like molecules in infection, inflammation, and metabolic disorders. Cytokine 110 442-451. (https://doi.org/10.1016/j. cyto.2018.05.014)

Raggi F, Pelassa S, Pierobon D, Penco F, Gattorno M, Novelli F, Eva A, Varesio L, Giovarelli M \& Bosco MC 2017 Regulation of human macrophage M1-M2 polarization balance by hypoxia and the triggering receptor expressed on myeloid Cells-1. Frontiers in Immunology 81097. (https://doi.org/10.3389/fimmu.2017.01097)

Reidy PT, Mckenzie AI, Mahmassani ZS, Petrocelli JJ, Nelson DB, Lindsay CC, Gardner JE, Morrow VR, Keefe AC, Huffaker TB et al. 2019 Aging impairs mouse skeletal muscle macrophage polarization and muscle-specific abundance during recovery from disuse. American Journal of Physiology: Endocrinology and Metabolism 317 E85-E98. (https://doi.org/10.1152/ajpendo.00422.2018)

Richards JS, Russell DL, Ochsner S, Hsieh M, Doyle KH, Falender AE, Lo YK \& Sharma SC 2002 Novel signaling pathways that control ovarian follicular development, ovulation, and luteinization. Recent Progress in Hormone Research 57 195-220. (https://doi.org/10.1210/rp.57.1.195)

Rosenberg HF, Dyer KD \& Foster PS 2013 Eosinophils: changing perspectives in health and disease. Nature Reviews: Immunology $\mathbf{1 3}$ 9-22. (https://doi.org/10.1038/nri3341)

Russell DG, Huang L \& Vanderven BC 2019 Immunometabolism at the interface between macrophages and pathogens. Nature Reviews: Immunology 19 291-304. (https://doi.org/10.1038/s41577-019-0124-9)

Salam N, Rane S, Das R, Faulkner M, Gund R, Kandpal U, Lewis V, Mattoo H, Prabhu S, Ranganathan V et al. 2013 T cell ageing: effects of age on development, survival \& function. Indian Journal of Medical Research 138 595-608.

Salvioli S, Monti D, Lanzarini C, Conte M, Pirazzini C, Bacalini MG, Garagnani P, Giuliani C, Fontanesi E, Ostan R et al. 2013 Immune system, cell senescence, aging and longevity--inflamm-aging reappraised. Current Pharmaceutical Design 19 1675-1679. (https://doi. org/10.2174/138161213805219531)
Saule P, Trauet J, Dutriez V, Lekeux V, Dessaint JP \& Labalette M 2006 Accumulation of memory $T$ cells from childhood to old age: central and effector memory cells in CD4(+) versus effector memory and terminally differentiated memory cells in CD8(+) compartment. Mechanisms of Ageing and Development 127 274-281. (https://doi.org/10.1016/j. mad.2005.11.001)

Shi C \& Pamer EG 2011 Monocyte recruitment during infection and inflammation. Nature Reviews: Immunology 11 762-774. (https://doi. org/10.1038/nri3070)

Skaznik-Wikiel ME, Swindle DC, Allshouse AA, Polotsky AJ \& McManaman JL 2016 High-fat diet causes subfertility and compromised ovarian function independent of obesity in mice. Biology of Reproduction 94 108. (https://doi.org/10.1095/biolreprod.115.137414)

Snider AP \& Wood JR 2019 Obesity induces ovarian inflammation and reduces oocyte quality. Reproduction 158 R79-R90. (https://doi. org/10.1530/REP-18-0583)

Stein M, Keshav S, Harris N \& Gordon S 1992 Interleukin 4 potently enhances murine macrophage mannose receptor activity: a marker of alternative immunologic macrophage activation. Journal of Experimental Medicine 176 287-292. (https://doi.org/10.1084/jem.176.1.287)

Thomas FH \& Vanderhyden BC 2006 Oocyte-granulosa cell interactions during mouse follicular development: regulation of kit ligand expression and its role in oocyte growth. Reproductive Biology and Endocrinology 4 19. (https://doi.org/10.1186/1477-7827-4-19)

Turner EC, Hughes J, Wilson H, Clay M, Mylonas KJ, Kipari T, Duncan WC \& Fraser HM 2011 Conditional ablation of macrophages disrupts ovarian vasculature. Reproduction 141 821-831. (https://doi.org/10.1530/REP10-0327)

Van Dyken SJ \& Locksley RM 2013 Interleukin-4- and interleukin-13mediated alternatively activated macrophages: roles in homeostasis and disease. Annual Review of Immunology 31 317-343. (https://doi. org/10.1146/annurev-immunol-032712-095906)

Van Kempen TA, Milner TA \& Waters EM 2011 Accelerated ovarian failure: a novel, chemically induced animal model of menopause. Brain Research 1379 176-187. (https://doi.org/10.1016/j.brainres.2010.12.064)

Wise PM, Smith MJ, Dubal DB, Wilson ME, Rau SW, Cashion AB, Bottner M \& Rosewell KL 2002 Neuroendocrine modulation and repercussions of female reproductive aging. Recent Progress in Hormone Research $\mathbf{5 7}$ 235-256. (https://doi.org/10.1210/rp.57.1.235)

Wood N, Whitters MJ, Jacobson BA, Witek J, Sypek JP, Kasaian M, Eppihimer MJ, Unger M, Tanaka T, Goldman SJ et al. 2003 Enhanced interleukin (IL)-13 responses in mice lacking IL-13 receptor alpha 2. Journal of Experimental Medicine 197 703-709. (https://doi.org/10.1084/ jem.20020906)

Wu D, Molofsky AB, Liang HE, Ricardo-Gonzalez RR, Jouihan HA, Bando JK, Chawla A \& Locksley RM 2011 Eosinophils sustain adipose alternatively activated macrophages associated with glucose homeostasis. Science 332 243-247. (https://doi.org/10.1126/science.1201475)

Wu R, Van Der Hoek KH, Ryan NK, Norman RJ \& Robker RL 2004 Macrophage contributions to ovarian function. Human Reproduction Update 10 119-133. (https://doi.org/10.1093/humupd/dmh011)

Wynn TA \& Vannella KM 2016 Macrophages in tissue repair, regeneration, and fibrosis. Immunity 44 450-462. (https://doi.org/10.1016/j. immuni.2016.02.015)

Yu W, Chen J, Xiong Y, Pixley FJ, Yeung YG \& Stanley ER 2012 Macrophage proliferation is regulated through CSF-1 receptor tyrosines 544, 559, and 807. Journal of Biological Chemistry 287 13694-13704. (https://doi. org/10.1074/jbc.M112.355610)

Zhao Y, Zou W, Du J \& Zhao Y 2018 The origins and homeostasis of monocytes and tissue-resident macrophages in physiological situation. Journal of Cellular Physiology 233 6425-6439. (https://doi.org/10.1002/ jcp.26461)

Received 30 July 2019

First decision 17 September 2019

Revised manuscript received 22 December 2019

Accepted 14 January 2020 